AAOUJ

13,1

88

Received 19 January 2018

Revised 22 March 2018

27 March 2018

7 April 2018

Accepted 11 April 2018

\section{Research on the construction of seamless learning platform based on open education}

\author{
Yongrong Xin \\ Business School, Jiangsu Open University, Nanjing, China and \\ Katz Graduate School of Business, Pittsburgh University, Pittsburgh, \\ Pennsylvania, USA, and \\ Xiuping Zuo and Qingping Huang \\ Business School, Jiangsu Open University, Nanjing, China
}

\begin{abstract}
Purpose - The implementation of the national education and lifelong education should break through the traditional learning mode in the digital era. A seamless learning environment is the intelligent form of deep integration of digital learning environment and physical learning environment. The development and construction of seamless learning space and platform is a new trend of international mobile learning research and practice. So, the purpose of this paper is to build a seamless learning platform of the open education system by expanding and improving the connotation and extension of seamless learning, based on the theories of mobile learning, ubiquitous learning and open education, combining with the characteristics of the big data era. Design/methodology/approach - A seamless learning platform model will be constructed through constructing five modules including resource integration module, requirement module, management module, teacher integration module, and carrier module, using interdisciplinary research methods (combined with economics), functional analysis, model methods and exploratory research methods. Finally, this paper attempts to realize the application of a seamless learning platform in open education through the strategic path of public-private partnership (PPP).

Findings - Seamless learning platform model given by this paper can effectively eliminate the problem of information asymmetry between learner-demander and educational manager through the effective management of carrier fusion module. Furthermore, it can effectively integrate the learning resources and teachers of the open education system and social individual education system, and provide high-quality shared learning resources and diverse stratification teachers to students and social workers through PPP project cooperation ways.

Originality/value - There are many papers on the study of open education and resource construction. However, few papers have studied how to effectively integrate and optimize various existing scattered online resources, including various system courses, teachers and platform systems. The paper provides an effective way to solve the above sub-problems and the realization path/model reference for the effective and accurate promotion of lifelong sustainable learning for all.
\end{abstract}

Keywords Mobile learning, Open education, Seamless learning platform, Ubiquitous learning

Paper type Research paper

\section{Introduction}

With the further development of social informatization, ever-changing technologies, such as internet and cloud platforms, change people's thinking, learning, production and lifestyle profoundly. With the development of mobile technology and rapid change in people's lifestyle, various teaching modes taking the network as the platform are becoming popular in the world and have gradually become an important means for people to obtain instant

\footnotetext{
(C) Yongrong Xin, Xiuping Zuo and Qingping Huang. Published in the Asian Association of Open Universities Journal. Published by Emerald Publishing Limited. This article is published under the Creative Commons Attribution (CC BY 4.0) licence. Anyone may reproduce, distribute, translate and create derivative works of this article (for both commercial \& non-commercial purposes), subject to full attribution to the original publication and authors. The full terms of this licence may be seen at http:// creativecommons.org/licences/by/4.0/legalcode
}

Asian Association of Open Universities Journal Vol. 13 No. 1,2018 pp. $88-99$ Emerald Publishing Limited 2414-6994 DOI 10.1108/AAOUJ-01-2018-0005 
fragmentation based on knowledge, which has become a new hotspot in the direction of the development of education teaching. At present, education, economic and social developments are more closely related, and the concepts of people's study, lifelong learning and individualized learning are becoming more and more popular. In the "development of national education in 13th Five-Year plan" in 2017, the State Council pointed out that it will actively promote the development of "Internet plus education" to promote the digital educational resources generally open and to share digital educational resources to public services (Chunyu, 2016). At present, the learner's education mode, form, content and way of learning are undergoing profound changes; education governance presents multi-party cooperation, broad participation, and hundred flowers of the unprecedented event. How to integrate the current social education and learning resources effectively, eliminate information asymmetry, to build a lifelong learning platform to provide seamless, and ladder civilian progress are the key to enrich themselves and enhance the power supply stations. Therefore, it is profound how to build a lifelong learning platform for the seamless construction of the open education system.

\section{Related literature review}

Seamless learning has evolved from mobile learning to ubiquitous learning. It is an intelligent learning state which is based on the integration of information technology means and equipment, physics learning environment and digital learning resources. Therefore, the construction of technology and platform is the foundation; the development of seamless learning requires close integration and integration with related technologies.

The authors of this literature are mostly researchers and technicians in computer engineering and information engineering. Zhaojun et al. (2014) learnt from the seamless learning mode in the teacher-student interaction, and observed the contents of the two aspects of the cognitive interaction, then they designed an interactive $\mathrm{PC}$ and android mobile phone terminal system based on feedback, using the technology acceptance model to design the questionnaire, and used the questionnaire survey and interviews to collect data. This technology design has a higher acceptance level in students' learning and application. It has a positive effect on the effect of learning; Yushuang Dong, Yingqun Liu, and Xibin Han of Tsinghua University have constructed a seamless learning model supporting the conceptual framework and software architecture of the environment (Yushuang et al., 2016). And applied the system architecture to "Tsinghua Education Online" (THEOL). They found that the seamless learning model required seamless switching between fixed scene learning terminal devices and terminal devices that support mobile scene learning. The construction of a seamless learning environment requires an organic integration of a fixed learning platform and a mobile learning platform environment, seamlessly integrated with third mainstream mobile applications (such as WeChat public title). It can be realized that after seamless integration, seamless switching between platforms, sharing of resources and data synchronization between learning process and behavior are observed. In the teaching application, it proved that the conceptual framework and the software architecture of the seamless learning environment are effective and feasible. Fang et al. (2016) proposed the seamless learning design model based on it is the foundation of freedom), the development of learner, learning resources center, service center, assessment center and cultural center. Kinshuk proposed the $5 \mathrm{R}$ Adaptation Framework (5 R adaptive framework): at the right time, at the right place, through proper mobile devices, to provide the right learners with the right content (Fang et al., 2016). Tan et al. (2011) constructed a context aware adaptive seamless learning system framework based on the $5 \mathrm{R}$ adaptive framework for learners to carry out personalized mobile learning. This seamless learning system architecture provides a standardized basis and important reference for the construction of a seamless learning platform in the future.
Construction of seamless learning platform 
AAOUJ

13,1

From the related literature review, the study of seamless learning is still in the initial stage and exploration stage. However, it is developed based on mobile learning and extensive learning; there is a certain research basis. Related technologies, such as sensor networks and internet of things, are being applied to the construction of platform and space, which verifies the feasibility of the technology. The research of technology support and design, model and resource construction is developing constantly, so the factor system of seamless learning platform is becoming more and more perfect in research and practice. From the above research review, there are still some key aspects which have not been paid attention to: first, more research works have focused on the exploration of norms, techniques, and patterns. No research has been done on effective integration and seamless docking of existing resource systems, management systems, faculty systems, and learner needs libraries. Second, the research on the construction of seamless learning platform is more limited to the construction of technology platform, and the resource utilization is mainly based on the independent resource pool built by a single educational institution. Because seamless learning has evolved from mobile learning to ubiquitous learning based on function and strives to achieve the purpose of improving the effect of derivative, so whether it is teachers, resources, management, demand, and ubiquitous elements of learning, mobile learning all have the same characteristics to a certain extent. Especially as the internet big data era characteristics, social power presents a self-ignition state in the process of specialized teaching and learning resources; the main body of education is no longer confined to educational institutions such as schools. Therefore, it has important practical significance to construct a truly seamless lifelong education learning platform, and know how to effectively integrate the scattered educational resources in the society and regulate them through the government and educational institutions, to reduce the asymmetry between resource suppliers and demanders.

On the basis of the above reviews and theoretical analysis, this paper attempts to break through the following two aspects: first, it will construct a platform conceptual framework of "seamless learning" through the development and improvement of the connotation and scope of the seamless learning platform. In addition to the traditional teachers, learners, technology and resources, the framework focuses on the expansion and management of teachers and resources, and the construction of learners' needs database. Innovatively, we attach importance to the role of management function in the whole framework; second, it will construct the conceptual model of a seamless learning platform and attempts to realize the application of seamless learning platform in open education through the strategic path of public-private partnership (PPP).

\section{Model construction}

\subsection{The connotation development of seamless learning}

From the existing literature research, the concept of "seamless" in seamless learning is mainly reflected in the seamless integration of the three latitudes of time, space and mode, including the integration of classroom learning and extracurricular learning integration, instant communication and non-instant communication, cross-fusion space physical state of learning, the real world and virtual reality (Junliang, 2014), the fusion of formal learning and informal learning, and the integration of a variety of teaching methods and activities.

From the above three aspects of integration, we can see that the original "seamless" concept only focuses on the docking and diversification of learning methods, without taking into account the seamless integration of resources supplies and demand, and seamless integration of teachers and learners. Thus, there are still some shortcomings in exposing the connotation of seamless learning: the limitation of resource supply, and the asymmetry of resource supply and search. The social elites build a course on the web, but fail to track down target customers, as it is difficult for people who have learning needs to match their high-quality resources in the vast amount of information resources. 
Starting from increasing the quality and diversity of the supply of resources and reducing the information asymmetry of the supply side of demand, this paper integrates the learner needs module and the management support module into the seamless learning platform. Education and learning resources are no longer merely provided by school teachers, but expand the scope of teachers (Huixin, 2015). It is no longer limited to school teachers, but consists of teachers from various reputed institutions of the community and industry. School depends on three factors: platform, teachers, and resources. Building a bridge between social teachers and learning needs, and introducing a demand database can eliminate the information asymmetry between supply and demand from the information supply of demand side. The elements and connotations of the seamless learning platform before and after the expansion are shown in Figures 1 and 2.

\subsection{Basic assumptions of the model}

A reasonable hypothesis is the basis and premise of the analysis model formation. The model of seamless learning platform based on open education perspective is mainly based on the following basic assumptions:

Assumption 1. Participants in education (educators and learners) conform to Smith's hypothesis of economic person and the hypothesis of a rational person to some extent. Both educators and learners expect to pursue and maximize economic benefits at the lowest cost. The effective way to maximize social benefits is exchanging resources under the background of "Internet + " open education.
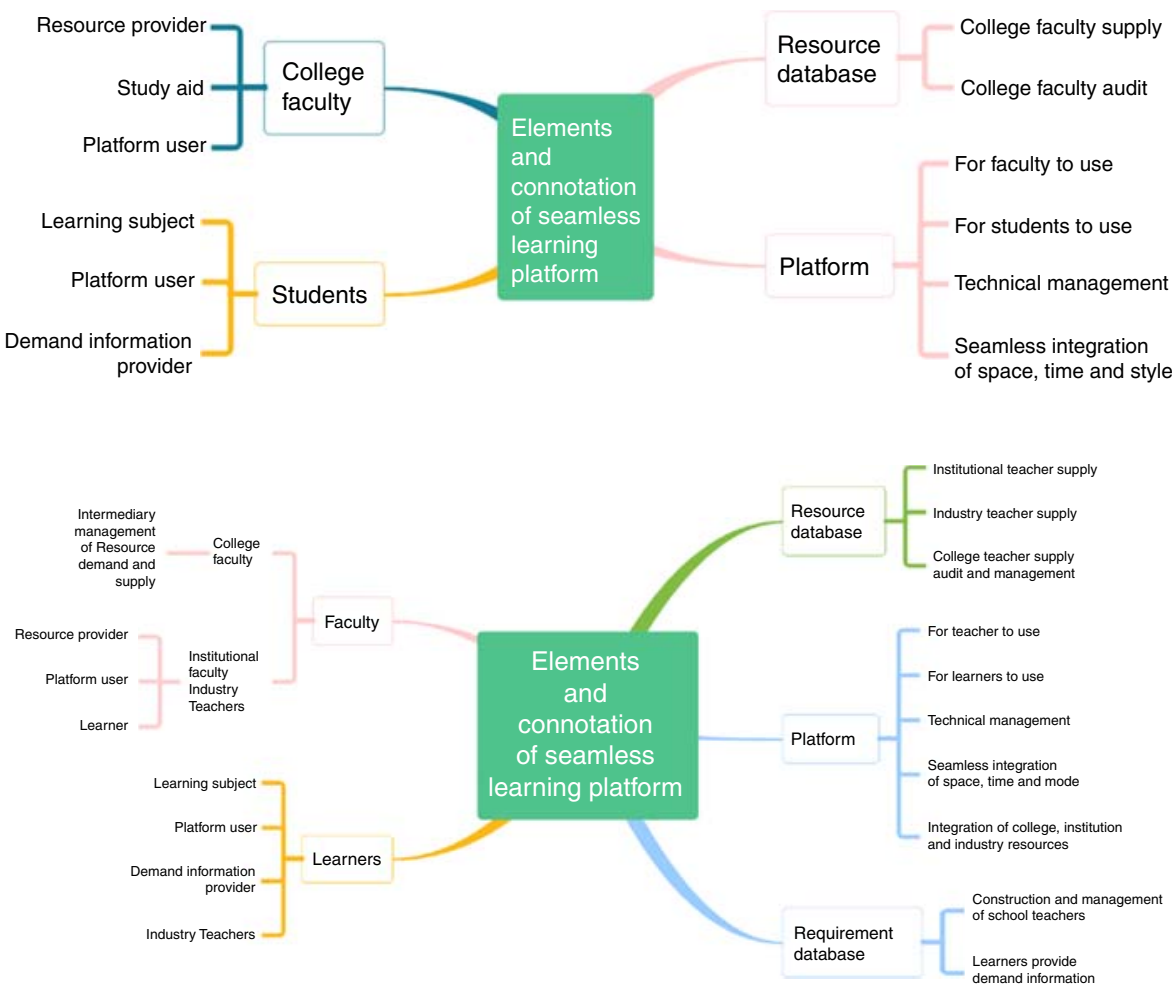

Figure 2.

The extended elements and connotation of seamless learning platform
Construction of seamless learning platform
Figure 1.

The elements and connotation of seamless learning platform 
AAOUJ

13,1

92

Assumption 2. Knowledge field's efficience, allocation and implementation follow the scientific management theory. The process of learning seamlessly is consistent with the management of Taylor proposed management assumptions. Taylor put forward that the interests of both parties are consistent. Increasing workers' income can increase labor productivity, thereby reducing unit time costs. It is a win-win process.

Assumption 3. Open education field also has an information asymmetry.

Assumption 4. Government and Universities are the watchers of open education promotion and educational equity.

\subsection{Construction of the seamless learning platform model}

Based on the above theoretical analysis and hypothesis, this paper constructs a seamless learning platform including five modules: resource module, demand module, teacher integration module, carrier module and management module. The construction process is as follows.

3.3.1 Resource integration module. At present, sharing economy has become China's new economic model, such as sharing bicycles, sharing power bank, sharing cars and so on. The application of shared mode is more and more extensive, permeating into the educational field, such as sharing courses, sharing books, sharing educational resources and so on. The introduction of shared education concept has important practical significance for the advancement of open education for all. In a person's life, formal education takes up about 20 percent of the time, mainly in school and professional skills, the remaining 80 percent hours are in the informal learning state. The purpose of later learning is diversity, including all aspects of human life (Daoming, 2016), work needs, etc. In formal education, relevant teachers at school mainly provide education resources. While in the informal education, the sources of educational resources are very rich. As a result of the diversity of the learning purpose, a large quantity of diversity and inclusiveness of the demand resources are derived. At this point, if the educational resources are still supplied by the teachers, it is obviously impossible to meet the needs of the open learners, especially the diversity. At the same time, it will also increase the pressure on teachers' resources supply, and reduce the quality of curriculum resources. In fact, the supply of educational resources is not limited to teachers. At the moment when mobile terminals are widely used, open education learners can also be the designers and providers of educational resources. But their learning and education are separated into different fields. Person A, a learner with flower arranging learning needs, is also an English-speaking practitioner. She is also a teacher of spoken English while seeking and using flower arranging learning resources (Qingyuan et al., 2016). At the same time, there is always such a flower arranging teacher, person $\mathrm{B}$, in a corner of the world; she has spoken English learning needs for various reasons. These elites, both of them, are scattered in all walks of life. Because they have many years of experience and industry background, it is the most suitable for them to provide learning resources for their industry and occupation, so as to realize the sharing and dissemination of resources. Such resources are what we call social personal resources.

In the resource integration module, three party resources are mainly integrated: school resources, training institutions resources, and social personal resources. We can provide the shared resource platform and entrance for the open education needs through the integration of these three types of resources, so as to realize the socialized organization of the open education resources, and keep the dynamic, generative, continuous development and evolution ability of the learning resources.

In the process of resource integration and socialization, the school identity which has undertaken most of the functions of open education has changed to a certain extent: in addition to continuing to take part in the provision and guidance of educational resources, 
we also need to undertake the screening of the other two types of resources. Resource access standards need to be set for the newly integrated resources, thus ensuring the quality of the shared resources on the seamless learning platform. In addition, the integration of social curriculum resources is a huge process, therefore, the strong support of the local government education authorities in policy and finance is a strong guarantee for the smooth integration of open education resources (Figure 3).

3.3.2 Requirement module. Demand module is the foundation of an open education seamless learning platform. Effective individual demand defines the direction for the provision of open educational resources, therefore, the purpose of the demand module construction is to tap the learning needs of people's open education (Song, 2016), let these implicit demands be dominant, and keep links with these potential needs learners, so as to realize the matching of supply and demand of curriculum resources (Figure 4).

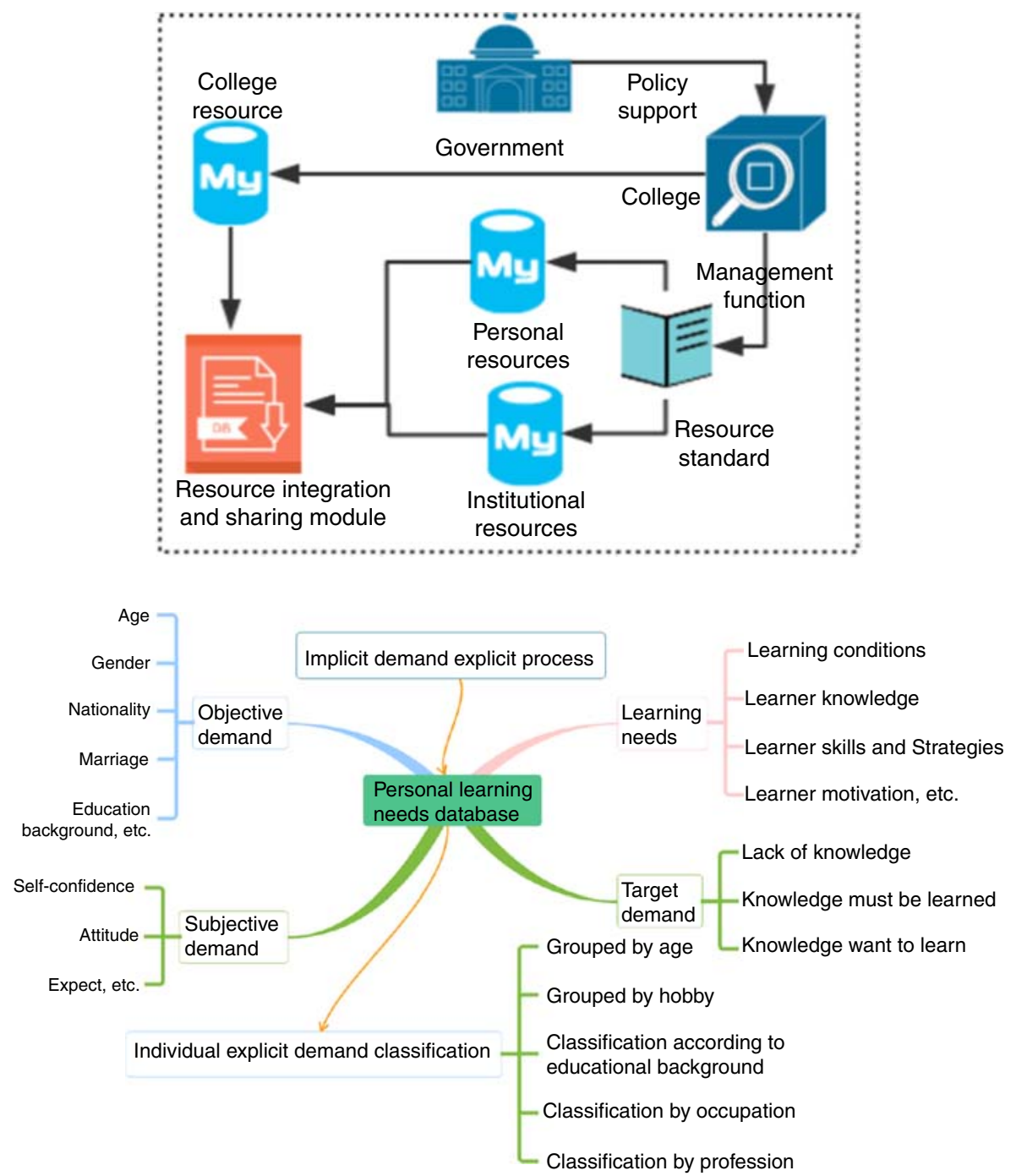

Construction of seamless learning platform

Figure 3.

Resource integration and sharing module

\section{Requirements module} building process 
AAOUJ

13,1

Brindley (1989) argued that demand includes both objective and subjective needs. The learners' personal information, such as age, sex, nationality, marriage, educational background, or the occupation to be engaged in, is an objective requirement, while learners are concerned with cognitive and emotional needs, such as self-confidence, attitudes, and expectations, they are summed up as subjective needs. At the same time, he also refined the target requirements into necessities, lack of knowledge and wants. Learning needs include learning conditions, learner knowledge, learner skills and strategies, and learner motivation. The construction of demand database is the basis of matching educational resources. And perfect personal data information is helpful to construct learners' personalized learning model, and effective analysis and prediction of learners' learning performance also provide the best reference data for personalized learning support services. At the same time, the high matching of resource supply and demand is also an effective guarantee for the late learning effect of the seamless learning platform.

One of the factors that need to be considered in the learning requirements module is the guidance of the students' participation in the technology strategy. Because learners have different characteristics, the learning effect will be different due to different learning strategies. In order to guarantee the learning effect, it is necessary to guide students according to their personal characteristics (Yanhui et al., 2015). This part of the guidance needs to accumulate through the student's learning characteristics over a period of time. Let the computer capture-related data in the background, and then summarize its characteristics so as to recommend learning strategies.

In this way, we construct the requirement database of learners in open education according to the construction goal of the demand module, and the classification of learners' needs, the learners' objective needs, subjective needs, and target requirements are discussed. There are many ways to obtain personal information and learning needs, such as interviews, registration, surveys, etc. Combined with the widespread use of mobile phone terminals, the most effective way is through the investigation of electronic questionnaires, such as questionnaires, and stars online survey.

3.3.3 Teacher integration module. In the current open education system, the responsibilities of education lie mainly in open education, community education and training institutions, and the Open University has undertaken most of the pre-job and post-career education needs. The majority of other non-academic education needs tend to search the Internet for educational resources that fit their needs. In the process of building a seamless learning platform, the integration of resources and the integration of teachers are also processed at the same time; therefore, the process of resource screening is also the process of selecting and integrating teachers. Because on the seamless learning platform, most of the functions of school teachers are not limited to the construction and supply of teaching resources; there is a transformation of functions, i.e. they are expected to shoulder the management function of the platform. Therefore, it is necessary to constantly expand the faculty of open education. Which is similar to the integration and expansion of curriculum resources, teacher's module is mainly to integrate teachers, institutions, and social individual teachers.

Teachers mainly shoulder the management functions of curriculum resources and teachers. And social individual teachers have become an important role of teachers in open education (Haojun and $\mathrm{Xu}, 2016$ ), thus completing the transformation of the role of teachers in schools. At the same time, the open education has also been pushed into the society completely by individual teachers and learners. Some elite individuals tend to play both parts. Not only can we get the further expansion of knowledge from the open education wave, but also get additional knowledge gains from the role of teachers. Appreciating the sacred personal mission in promoting the open education, teaching and learning promotes each other and forms a virtuous circle (Figure 5). 


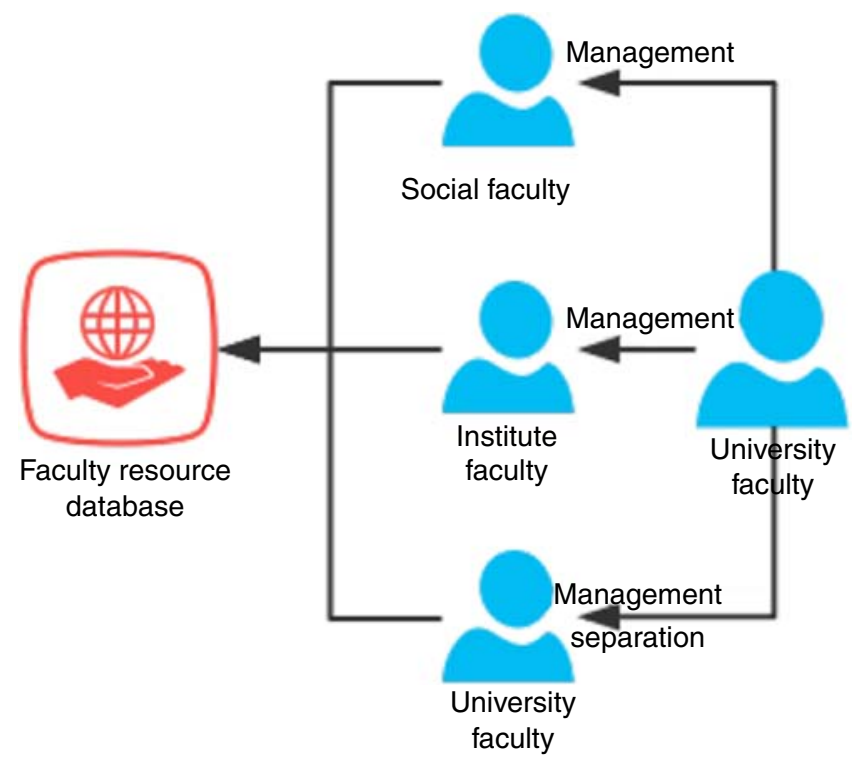

Construction of seamless learning platform

95

3.3.4 Management module. The management module is an important factor in the seamless learning platform. This module carries the management of teachers, platforms, students, and resources. It also bears the formulation of resource standards and teacher standards, as well as the bridge between supply and demand. In the module of teacher integration, we refer to a partial change in the functions of teachers, from learning designers, students and resource supply functions, to management functions (Qing, 2016). They are the builders, implementers, drivers, managers, and supervisors of the entire platform. The government's related education sector is a strong support and booster; they help to promote the road of open education based on the policy and finance. The management module mainly includes: user management system, platform management system, curriculum resource management system and teacher management system. Its functions are shown in Figure 6.

3.3.5 Carrier module. Effective seamless learning relies on the construction of intelligent platform space, that is, the physical support space that combines the above four modules into a whole. The key to the carrier module is to build the platform, post technical support and update the system, including intelligent learning terminals, storage cloud, education cloud computing center, etc. At present, the architecture of learning platform space is becoming more and more mature, and widely used in a variety of learning organizations, and the difference lies in the functional design of perfection, ease of operation, and system compatibility. Once the platform is built, it is not for once and for all; it needs constant updates and maintenance, and compatibility continues to expand too. Technical support is needed at the same time, in order to cope with the technical difficulties encountered in the use of teachers and students, and improve the system according to the problems encountered continuously.

\subsection{Open education seamless learning platform system based on PPP model}

We integrated the teacher module, demand module, resource module and management module in the platform space supported by third-party technologies. So far, the module construction of the seamless learning platform has been completed, forming a physical 


\section{AAOUJ 13,1}

\section{6}

Figure 6.

Function and composition of management module

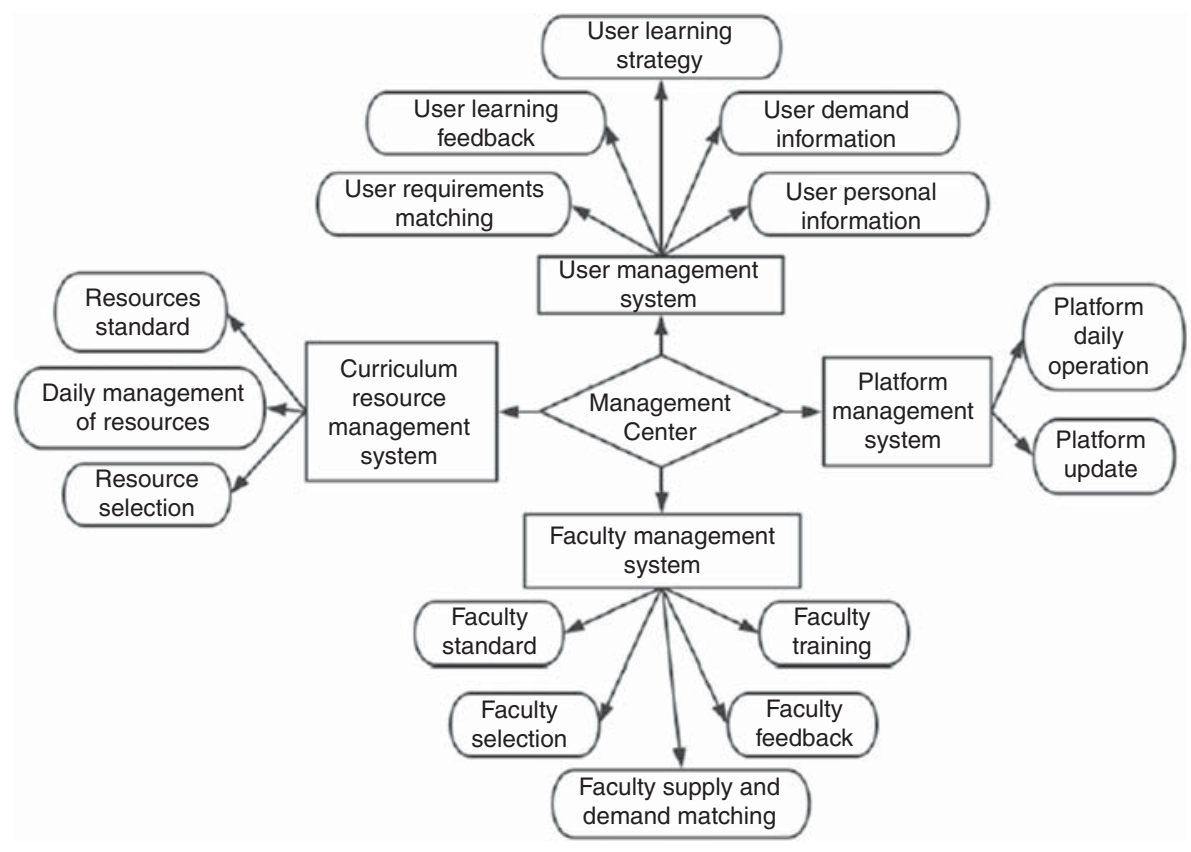

sense of seamless learning platform. Data flow process in platform space: the third-party technical support team maintains and updates the existing integration platform and keeps the dynamic extensibility of curriculum resource data. The backstage management system carries on the cloud computation to the demand module's demand data, then the curriculum resources and requirements information in the resource module are dynamically matched. At the same time, the teacher information is also matched. Next, a series of courses that match the needs of learners should be ranked according to the degree of matching, pushing the curriculum to the persons who need for decision making through the information and communication channels. Finally, the user learns the courses of interest at the user terminal interface (Figure 7).

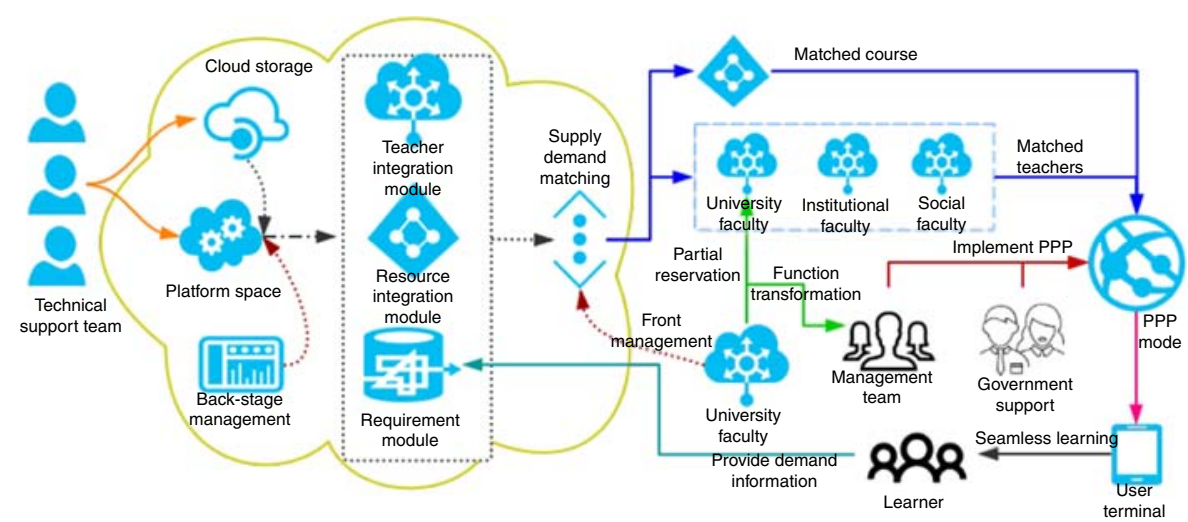

Figure 7.

Seamless learning platform system based on PPP mechanism 
Throughout the process, there are still some unsolved problems: the attribution of curriculum resources, the commitment of operating expenses, the ownership of tuition fees and the way of dealing with the supply and demand sides. It can be seen that school teachers will eventually change from the resource supply side to a platform operation management. Social individual will be the main force of curriculum resource supply and student support, and also the dual identity of learning needs. The government's relevant education departments provide policy and financial support to schools that bear management functions. The learners can learn courses by way of purchase, which will be shared by managers and teachers.

In this mode of operation, it will easily arise the following problems: as the school has become the main body of the seamless learning platform, the operating costs are all over the backlog. Teachers go back to similar employed parties and it is difficult for them to exert their initiative, and it is easy to cause the teachers to quit because the income is very small. Therefore, we can consider the employers as the main investment abroad except resource provider and student's identity. Because the service supply of seamless learning platform is to promote the development of open education, it is determined that its nature is not simply a profit-making product, but a similar public product and service. Therefore, we consider the introduction of government and social capital cooperation (PPP) model.

PPP model, means that, in the public service area, the government adopts a competitive approach to select social capital with investment and operational management capabilities. Both parties conclude the contract in accordance with the principle of equal consultation and provide public services from social capital. The government pays social capital according to the results of public service performance evaluation (Li and Cheng, 2015). It can promote the social individual teachers' enthusiasm to let them become investment and income side to a certain extent in the operation of the seamless learning platform system. The government, the school, the society, the individual, the teachers, the three parties participate in the whole process, and the teachers have deeper participation; this helps to eliminate the asymmetry of information and to achieve more favorable results than expected to act alone.

Throughout the process, PPP is not only a means of financing to promote diversification of the investment body, but also to support the school to bear the full cost of pressure, and share the operational risks of the government and the school; it improves the participation and master role of the teachers, more conducive to the whole seamless learning platform model running. However, the implementation of the PPP model is a complex system engineering, involving the cooperation and agreement between the school and the teachers; it is also a system mechanism change, involving administrative system reform, financial system reform, investment and financing system reform and so on. As space is limited, this is no longer explained here.

\section{Conclusions}

This paper constructs a seamless learning platform model including teacher integration module, demand module, resource integration module and management module based on the existing theories of mobile learning, ubiquitous learning and open education. And obtained the following conclusions: first, we build a platform element concept framework which can truly realize "seamless learning" by expanding and improving the connotation and scope of the seamless learning platform. The framework especially focuses on the expansion and management of teachers and resources, and the construction of learners' needs database, except including traditional teachers, learners, technology, and resources. In addition, innovatively, we attach importance to the role of management function in the whole framework; second, the model integrates school, social and institutions, i.e. three types of teacher resources. It effectively solves the problems of insufficient teacher resources
Construction of seamless learning platform 
AAOUJ

13,1

and excessive teaching pressure in the existing platforms. Third, the model integrates the curriculum resources of school, personal and institutional courses from three sides and solves the shortcomings. In the original platform, the school teachers are busy with the construction of curriculum resources all day long, and the quantity and quality cannot be taken into account. It cannot meet the shortcomings of the diversified needs of open education. Fourth, the model provides a matching basis for the supply and demand of resources through the construction of personal learning needs database, reducing the asymmetry of information and improving the efficiency and effectiveness of lifelong career construction effectively. Fifth, it proposes to operate the seamless learning platform through the PPP model, which will promote the diversification of investors. Besides, the participation and spirit of the teachers in the whole process have been improved that can reduce the running risk of the seamless learning platform. At the same time, it improves the supply quality and efficiency of the open education. It provides the basic guarantee for the lifelong sustainable learning of the whole people and provides a model reference for the realization of education for all.

However, there are still some problems unsolved due to limited space, such as it needs to provide learners with seamless learning strategies, learning model, learner learning process, tracking and control, and related data analysis, the rights and obligations between the management and the teachers in the PPP model, rules of cooperation, reform of administrative system, reform of financial system, reform of investment and financing system, etc.; the key technologies in the platform construction, such as sensor networks, Internet of things, and the application of emotion sensing technology, etc. In addition, these deficiencies pointed out the direction for follow-up research. In a word, the application of seamless learning model in the development of open education involves multidisciplinary collaboration, multi-industry collaboration, multi synergy, cross-technical collaboration, etc., the road ahead is still a long way to go.

\section{Acknowledgments}

This work was carried out with the aid of grants: 2016 Jiangsu University Philosophy and Social Sciences Research Fund Project (2016SJB880031), 2017 Jiangsu Provincial Higher Education Reform Research Project (2017JSJG396), 2017 Jiangsu Provincial Social Education Planning Project Key Project (JSS-B-2017003), 2017 Jiangsu Education Informatization Research Funding Project Youth Project (20172076), 2017 Jiangsu Province Outstanding Young and Middle-aged Teachers and Headmasters of Universities Project, 2016 Jiangsu University of Education Teaching Reform Research Project (16-YB-15), 2016 Jiangsu Provincial Social Education Planning Project (JSS-L-2016001), 2017 Jiangsu Provincial Institute for Lifelong Education initiated the project (17SZJA002).

\section{References}

Brindley, L. (1989), "Effects of rain and fly harassment on the feeding behaviour of free-ranging feral goats", Applied Animal Behaviour Science, Vol. 24 No. 1, pp. 31-41.

Chunyu, D. (2016), "Knowledge mapping of international ubiquitous learning field”, Modern Distance Education Research, Vol. 1 No. 1, pp. 85-95.

Daoming, F. (2016), "Ubiquitous learning activities of the knowledge flow model construction - based on the information dissemination model", Journal of Distance Education, Vol. 2 No. 34, pp. 73-81.

Fang, L., Yin, X. and Zhang, J. (2016), "Open universities from the perspective of seamless learning environment design", Journal of Distance Education, Vol. 2 No. 34, pp. 39-48.

Haojun, L. and Xu, J.C. (2016), "Application research of personalized mobile learning path optimization strategy”, Audio-visual Education Research, Vol. 1 No. 37, pp. 39-44. 
Huixin, L. (2015), "Seamless learning: a new trend of learning in the digital age", Modern Educational Science: Secondary School Teachers, Vol. 5 No. 1, pp. 31-32.

Junliang, L. (2014), "Study on the application of seamless learning strategy in blended learning environment”, Modern Educational Technology, Vol. 2 No. 24, pp. 42-48.

Li, W. and Cheng, H. (2015), "Research on current situation and problems of Chinese PPP mode", Modern Industrial Economy and Information Technology, Vol. 13 No. 1, pp. 5-7.

Qing, L. (2016), "Research on collaborative learning architecture construction under the background of continuing education", Audio-Visual Education Research, Vol. 1 No. 37, pp. 91-96.

Qingyuan, W., Zhan, C., Wang, F.L., Wang, S. and Tang, Z. (2016), "Clustering of online learning resources via minimum spanning tree", Asian Association of Open Universities Journal, Vol. 11 No. 2, pp. 197-215.

Song, T. (2016), "Research on content presentation model of mobile learning based on light application - taking 'waterfall flow' layout experience as an example”, Audio-Visual Education Research, Vol. 37 No. 2, pp. 31-37.

Tan, Q., Kinshuk, Z. and McGreal, R. (2011), "The 5 R adaptation framework for location-based mobile learning systems", Proceeding of 10th World Conference on Mobile and Contextual Learning, pp. 87-94.

*Yanhui, H.S., Wei, S. and Zhang (2015), "Analysis of online learning behaviour from a tutor perspective: reflections on interactive teaching and learning in the big data era1", Asian Association of Open Universities Journal, Vol. 10 No. 2, pp. 29-48.

Yushuang, D., Liu, Y. and Han., X. (2016), "Seamless learning model and its supporting environment. Application of technical framework", Modern Distance Education Research, Vol. 4 No. 1, pp. 70-79.

Zhaojun, D., Zhao, Y., Liu, H., Zhang, J. and Ma., J. (2014), "Research on the design and application of interactive feedback system in seamless learning environment", Modern Educational Technology, Vol. 3 No. 1, pp. 107-114.

\section{Further reading}

13th Five-Year (2017), "The State Council issued the 'National Education Development Plan'”, people.com.cn: People's Daily, Vol. 1 No. 20, pp. 25-33.

\section{Corresponding author}

Yongrong Xin can be contacted at: xinyongrong@126.com

For instructions on how to order reprints of this article, please visit our website: 